\title{
Aberrant regulation of the LIN28A/LIN28B and let-7 loop in human malignant tumors and its effects on the hallmarks of cancer
}

Tianzhen Wang ${ }^{1 \dagger}$, Guangyu Wang ${ }^{2+}$, Dapeng Hao ${ }^{3+}, \mathrm{Xi} \mathrm{Liu}^{4 \dagger}$, Dong Wang ${ }^{5^{*}}$, Ning Ning ${ }^{6 *}$ and Xiaobo $\mathrm{Li}^{\mathrm{i}^{*}}$

\begin{abstract}
RNA binding proteins (RBPs) and microRNAs (miRNAs) are two of the most important post-transcriptional regulators of gene expression, and their aberrant expression contributes to the development of human malignancies. Let-7, one of the most well-known tumor suppressors, is frequently down-regulated in a variety of human cancers. The RBP LIN28A/LIN28B, a direct target of the let-7 family of miRNAs, is an inhibitor of let-7 biogenesis and is frequently up-regulated in cancers. Aberrant regulation of the LIN28A/LIN28B and let-7 loop in human malignant tumors is reportedly involved in cancer development, contributing to cellular proliferation, cell death resistance, angiogenesis, metastasis, metabolism reprogramming, tumor-associated inflammation, genome instability, acquiring immortality and evading immune destruction. In this review, we summarized the mechanisms of LIN28A/LIN28B and let-7 loop aberrant regulation in human cancer and discussed the roles and potential mechanisms of the LIN28A/LIN28B and let-7 loop in regulating the hallmarks of cancer. The crosstalk between LIN28A/LIN28B and let-7 loop and certain oncogenes (such as MYC, RAS, PI3KJAKT, NF-KB and $\beta$-catenin) in regulating hallmarks of cancer has also been discussed.
\end{abstract}

Keywords: RNA binding proteins, MicroRNAs, LIN28A/LIN28B and let-7 loop, Hallmarks of cancer

\section{A double-negative feedback loop between LIN28A/LIN28B and let-7}

MicroRNAs (miRNAs) are small non-coding RNAs that bind the mRNA of target genes to inhibit their translation and/or induce their decay. MicroRNAs thus play a crucial role in many biological events, including tumorigenesis. Briefly, most miRNAs are transcribed by RNA polymerase II [1]. Primary miRNA transcripts (pri-miRNAs) are then processed in the nucleus by the RNAseIII Drosha into 70-100-nt-long pre-miRNAs, which are then exported to the cytoplasm and cleaved by the RNAse III Dicer to form $~ 22$-nt-long dsRNAs (miRNA). Finally, the RNAinduced silencing complex (RISC) binds to one strand

\footnotetext{
* Correspondence: wangdong@ems.hrbmu.edu.cn; ningning301@126.com; lixiaobo@ems.hrbmu.edu.cn

${ }^{\dagger}$ Equal contributors

${ }^{5}$ College of Bioinformatics Science and Technology, Harbin Medical University, Harbin, China

${ }^{6}$ Department of Gastrointestinal Surgery, International Hospital of Pecking University, Beijing, China

${ }^{1}$ Department of Pathology, Harbin Medical University, Harbin, China Full list of author information is available at the end of the article
}

of the dsRNA and guides it to target mRNA for subsequent silencing [2].

The miRNA let-7 was identified in the nematode Caenorhabditis elegans in 2001, seven years after let-4, the first known miRNA, was identified in the same species [3]. The let-7 family of miRNAs is the largest of all miRNA families, and members of this family are highly conserved in sequence and function from C. elegans to humans $[4,5]$. It's now known that members of let-7 family play important roles in regulating cellular differentiation, metabolism and the development of certain diseases, including tumorigenesis [6].

The highly conserved RNA binding proteinLIN28 family includes two homologous members, LIN28A and LIN28B, each having similar domain structure and function. Like let-4 and let-7, LIN28A was also first identified in C.elegans [7], though it is also present in a wide variety of mammals. Notably, LIN28A gene mutation in C. elegans results in disturbance of its developmental timing [8]. LIN28B was first identified in hepatocellular carcinoma, where levels of the protein were high [9]. Recent studies found that LIN28A/LIN28Band let-7 family

\section{() Biomed Central}

(c) 2015 Wang et al. This is an Open Access article distributed under the terms of the Creative Commons Attribution License (http://creativecommons.org/licenses/by/4.0), which permits unrestricted use, distribution, and reproduction in any medium, provided the original work is properly credited. The Creative Commons Public Domain Dedication waiver (http:// creativecommons.org/publicdomain/zero/1.0/) applies to the data made available in this article, unless otherwise stated. 
miRNAs tend to have opposing roles in many cellular processes, in particular those involved in cancer development and progression [10]. Indeed, LIN28A/LIN28B and let-7 are inversely expressed in normal and malignant tissues $[11,12]$. The presence of a double-negative feedback loop between LIN28A/LIN28B and let-7 was also reported [10].

LIN28A/LIN28B negatively regulates let-7family miRNAs via its RNA-binding domains (RBDs), which include a cold-shock domain (CSD) at the N-terminus and two Cys-Cys-His-Cys (CCHC)-type zinc finger domains at the C-terminus [13-16]. Both the CSD and CCHC zinc fingers of LIN28A/LIN28B can interact with the conserved residues ofpri-let-7 and pre-let-7. Briefly, the CSD inserts into the apical point of the precursor loop, while the $\mathrm{CCHC}$ zinc fingers dimerize on a GGAG motif adjacent to the Dicer cleavage site $[17,18]$. The binding of LIN28A/LIN28B to either pri-let-7 or pre-let-7 inhibits let-7 precursor processing by Drosha and Dicer [19]. Upon binding to pre-let-7, LIN28A/LIN28B recruits TUT4/TUT7, which causes oligo-uridylation at the 3 'terminal of pre-let-7 [20-22]. Under normal conditions, Dicer recognizes the two-nucleotides at the 3' terminal via its PAZ domain; however, oligo-uridylation elongates the 3' terminal resulting in resistance to Dicer cleavage. Oligo-uridylated pre-let-7 can also be degenerated by the $3^{\prime}-5^{\prime}$ exonuclease Dis312 [23, 24]. Thus, LIN28A/LIN28B not only inhibits the biogenesis of let-7 family miRNAs, but also induces their degradation. Conversely, let-7 miRNA may bind complementary sites on the 3' UTR of both LIN28A and LIN28B mRNAs, thus inhibiting the expression and function of LIN28A/LIN28B protein $[9,25]$. This double-negative feedback loop between LIN28A/LIN28B and let-7 is shown in Fig. 1.

\section{The mechanisms of aberrant expression of LIN28A/LIN28B and let-7 in cancer}

LIN28A/LIN28B proteins are frequently up-regulated in various malignancies originating from three germ layers (Table 1). High levels of LIN28A/LIN28B proteins are associated with many cancer biological behaviors and poor prognosis.

LIN28A/LIN28B transactivation by various transcription factors in malignancies has been extensively studied. LIN28B may be up-regulated via direct promoter binding by the transcription factor c-myc upon activation of the MAPK signaling pathway [26] or by NF- $\mathrm{kB}$ during inflammation [27]. LIN28B may also be up-regulated by STAT3 during inflammation-mediated epithelial-to-mesenchymal transition (EMT) [28] or by $\beta$-catenin upon activation of the Wnt signaling pathway [29]. The transcriptional factor SOX2 reportedly up-regulates LIN28A by binding to a proximal site on the promoter and facilitating promoter acetylation via interaction with the histone acetyltransferase complex [30].

LIN28A/LIN28B is also regulated post-transcriptionally. In addition to let-7, the miRNAs miR-26a, miR-181, miR-9, miR-30, miR-125, miR-212 and miR-27 have also been shown to directly bind the 3'UTR of LIN28A/LIN28B and repress translation of the protein, and as these miRNAs are frequently under-expressed in malignant tumors, higher levels of LIN28 expression are seen [31-34]. Notably, a potential regulatory loop reportedly exists between LIN28B and miR-212 in androgen-independent prostate cancer

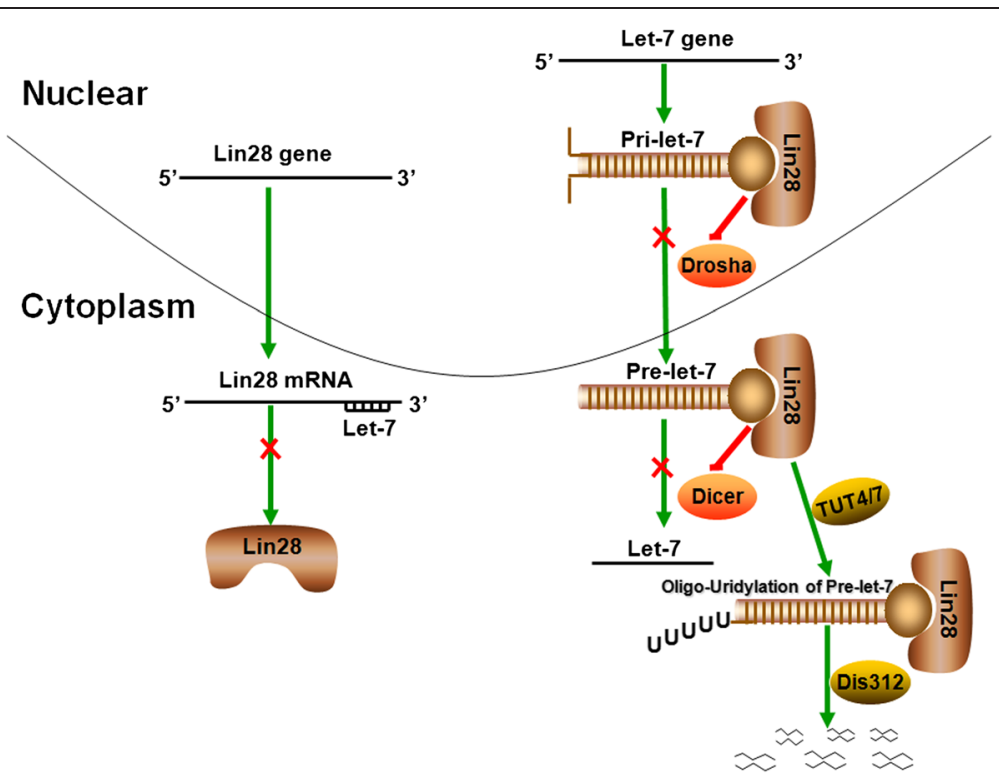

Fig. 1 A double-negative feedback loop between LIN28A/LIN28B and let-7 
Table 1 Pathological associations of increased LIN28A/LIN28B and or of decreased let-7 expression in various cancer tissues

\begin{tabular}{|c|c|c|c|c|}
\hline \multirow{2}{*}{$\frac{\text { Origin }}{\text { Endoderm }}$} & \multirow{2}{*}{$\begin{array}{l}\text { Cancer type } \\
\text { Colon }\end{array}$} & \multirow{2}{*}{$\begin{array}{l}\text { Ref. } \\
\text { LIN28 }\end{array}$} & \multicolumn{2}{|c|}{ Pathological association } \\
\hline & & & {$[12,74]$} & Increased tumor progression and metastasis \\
\hline & & Let-7 $\downarrow$ & {$[113,114]$} & Poor prognosis \\
\hline & Lung & LIN28个 & {$[12,115]$} & Increased proliferation \\
\hline & & Let-7 $\downarrow$ & {$[116]$} & Poor prognosis; increased cellular proliferation \\
\hline & Hepatocellular carcinoma & LIN28个 & {$[12,117]$} & Advanced-stage cancer \\
\hline & & Let-7 $\downarrow$ & {$[118]$} & Metastatic cancer; increased proliferation and migration \\
\hline & Gastric adenocarcinoma & LIN28个 & [119] & Poor prognosis \\
\hline & & Let-7 $\downarrow$ & {$[76]$} & Increased invasion and metastasis \\
\hline & Esophageal & LIN28个 & {$[75]$} & Increased proliferation and metastasis \\
\hline & Pancreatic & Let-7 $\downarrow$ & {$[120]$} & Increased proliferation \\
\hline \multirow[t]{9}{*}{ Mesoderm } & Cervical & LIN28个 & {$[12]$} & \\
\hline & Ovarian & LIN28个 & {$[12,121]$} & High-grade cancer \\
\hline & & Let-7 $\downarrow$ & {$[121,122]$} & High-grade cancer \\
\hline & Germ cell tumor & LIN28个 & [123] & Poor prognosis \\
\hline & Prostate & LIN28个 & [124] & Increased proliferation \\
\hline & & Let-7 $\downarrow$ & {$[125]$} & Increased proliferation \\
\hline & Chronic myeloid leukemia & LIN28个 & {$[12]$} & Increased tumor progression \\
\hline & Burkitt lymphoma & Let-7 $\downarrow$ & {$[126,127]$} & Increased proliferation \\
\hline & Renal cell carcinoma & Let-7 $\downarrow$ & {$[128]$} & Metastatic and high-grade cancer \\
\hline \multirow[t]{5}{*}{ Ectoderm } & Breast & LIN28个 & {$[12,55,129]$} & Increased tumor aggressiveness and proliferation \\
\hline & & Let-7 $\downarrow$ & {$[81]$} & Lymph node metastasis \\
\hline & Oral squamous cell carcinoma & LIN28个 & {$[90]$} & Poor prognosis \\
\hline & Glioma & LIN28个 & [130] & Increased proliferation \\
\hline & Melanoma &  & [131] & Increased invasion \\
\hline
\end{tabular}

[35]. A recent study revealed that LIN28A/LIN28B mRNA contains an AU-rich element (ARE) within its 3'UTR, and the tumor suppressor tristetraprolin (TTP), an ARE binding protein, enhances the degradation of LIN28A/LIN28B mRNA; however, TTP is often repressed in human cancers, which may also contribute to the elevation of LIN28A/ LIN28B in certain cancer types [36]. The ribonuclease DIS3, one of the most frequently mutated genes in multiple myeloma, is an inhibitor of LIN28B through binding and degrading LIN28B mRNA [37]. More recent research revealed that the expression of insulin-like growth factor 2 (IGF2) mRNA-binding protein 3 (IMP3), a protein which regulates RNA localization, translation and stability, correlates with that of LIN28B and cytoplasmic IMP3 granules contain LIN28B mRNA. Further studies showed that IMP3 recruits LIN28B mRNA and prevents the binding of argonaute 2 (Ago2) and let-7 to LIN28B, thus allowing the increased expression of it and other let-7 target genes, like HMGA2 [38]. Additionally, the protein level of LIN28B has been revealed to be regulated via ubiquitin-mediated proteasomal degradation. The human TRIM-NHL domaincontaining protein TRIM71, an ubiquitin ligase, was reported to negatively regulate the stability of LIN28B protein by catalyzing its polyubiquitination [39]. However, weather the regulation of LIN28B protein is altered in malignancies is still waiting for further experiments to reveal.

In contrast to the expression of LIN28A/LIN28B proteins, the expression of let- 7 family miRNAs is typical decreased in cancers (Table 1). While let-7 miRNAs may be regulated at multiple levels, most studies support the significance of their post-transcriptional regulation. For instance, during tumorigenesis, mature let-7 was found to be absent, whereas pri-let-7 was present at high levels, which suggests post-transcriptional regulation of mature let-7 [40]. As previously mentioned, LIN28A/LIN28B is a common post-transcriptional repressor of let-7 miRNAs. In addition to LIN28A/LIN28B proteins, the complex of NF90 and NF45 proteins can inhibit pri-let-7a processing into pre-let-7a by binding to pri-let-7a [41], while Ago proteins can bind and stabilize mature miRNAs and thereby increase let-7 levels [42]. Importantly, as the endonucleases Drosha and Dicer are essential for the processing of miRNA to maturation, factors 
influencing the activity or expression of these endonucleases impact the processing of miRNAs. For instance, Fas and TRAIL-R2 were reported to reduce the levels of mature let-7 miRNA by inhibiting the activities of Dicer [43] and Drosha [44], respectively.

Regulation of let-7 expression also occurs at the transcriptional level. Notably, the presence of a $\mathrm{CpG}$ island in the promoter region of let-7a-3, located on chromosome 22q13.31, allows for epigenetic regulation via DNA methyltransferases DNMT1 and DNMT3B $[45,46]$. The nuclear hormone receptor DAF-12, a transcriptional activator or repressor depending on the presence or absence of a DA (dafachronic acid) ligand, can directly modulate the transcription of certain let-7 miRNAs [47]. Conversely, let-7 miRNAs can repress DAF-12 expression by binding its 3'UTR, which suggests a complex feedback loop between DAF-12 and let-7 miRNAs [48]. In addition to being repressed for their expression, the antitumor functions of let-7 have also been attenuated in malignant tumor cells. Competing endogenous RNA (ceRNA) is a hypothesis driven by the reasoning that mRNA, transcribed pseudogenes and long non-coding RNA (lncRNA) compete for a limited pool of miRNAs [49]. Even though the hypothesis of ceRNA is challenged by some researchers recently [50], ceRNAs attenuating let-7-mediatedantitumor activity has been extensively reported. For example, the lncRNAH19 reportedly inhibits the bioavailability of let-7 family miRNAs through a molecular sponge mechanism [51]. A recent study also found that high-mobility group A (HMGA2), a noncanonical transcriptional factor, promoted lung cancer progression independent of its protein-coding function. Indeed, HMGA2 functions as a ceRNA, competing with the transforming growth factor beta receptor 3(TGFBR3) for let-7, thus allowing for the heightened expression of TGFBR3 and subsequent lung cancer progression [52].

As discussed, the expression patterns and functions of LIN28A/LIN28B and let-7 in malignancies are largely opposing and appear to compose a double-negative feedback loop regulating cancer progression.

\section{LIN28A/LIN28B and let-7 loop regulates the hallmarks of cancer}

Hanahan and Weinberg famously described ten biological capabilities acquired by cancer during development [53]. These include: sustaining proliferative signaling, resisting cell death, evading growth suppressors, inducing angiogenesis, enabling replicative immortality, activating invasion and metastasis, accumulating genome instability, inducing inflammation, reprogramming of energy metabolism and evading immune destruction [53]. To date, the LIN28A/ LIN28B and let-7 loop has been demonstrated to regulate almost all of these hallmarks.

\section{LIN28A/LIN28B and let-7 loop regulates cancer cell proliferation}

One of the most fundamental characteristics of cancer cells is their capacity for uncontrolled proliferation. Unlike normal cells, whose proliferation is strictly controlled to maintain homeostasis, cancer cells have developed the ability to sustain proliferative signaling, therein becoming masters of their own destinies [53]. Many studies of multiple cancer types have shown that LIN28A/LIN28B promotes the proliferation of cancer cells through five different mechanisms: up-regulation of cell cycle regulators, elevation of cellular proliferative signaling, activation of proliferation-associated transcription factors, facilitation of ribosomal protein synthesis and activation of cellular metabolism.

LIN28A/LIN28B has been demonstrated to up-regulate cell-cycle regulators in two ways. First, LIN28A/LIN28B directly binds and promotes the translation of numerous mRNAs encoding cyclins (cyclinA, cyclinB and cyclinD), cyclin-dependent kinases (CDK1, CDK2 and CDK4) and cell division cycle proteins (CDC2 and CDC20) [54]. Secondly, through repressing let-7, LIN28A/LIN28B indirectly up-regulates some cell-cycle regulators targeted by let-7, such as cyclinD1/2, CDK6, CDC34, CDC25a and Trim71 (a repressor of CDK inhibitor $1 \mathrm{~A}$ ).

LIN28A/LIN28B can elevate cellular proliferation signals in both let-7-dependent and -independent manners. Through inhibiting let-7, LIN28A/LIN28B can activate a variety of cellular proliferation signaling pathways. For instance, let-7 targets the IGF1 receptor and AKT2 to inhibit PI3K/AKT pathway activity and RAS to inhibit MAPK pathway activity. Thus, inhibition of let-7 by LIN28A/LIN28B would increase the activities of both pathways and, subsequently, increase proliferation. As a RNA binding protein, LIN28A/LIN28B also directly binds to and promotes the translation of IGF2. Recently, it was also found that LIN28A/LIN28B promotes the expression of human epidermal growth factor receptor 2 (HER2) at the post-transcriptional level in breast cancer cells [55].

Activation of transcriptional factors necessary for cellular proliferation in a let-7-dependent manner is another method by which LIN28A/LIN28B can increase proliferation. For instance, hepatitis $\mathrm{B}$ virus $\mathrm{x}$ protein (HBx) promotes cellular proliferation through downregulating let-7 expression, thus elevating levels of the transcription factor signal transducer and activator of transcription 3 (STAT3), another let-7 target, in HBV infected cells [56]. Additionally, let-7 represses the proliferation of cancer cells by directly targeting HMGA2, a protein which is frequently over-expressed in and promotes proliferation of many cancer types $[52,57,58]$.

LIN28A can also increase cellular proliferation through directly binding to and promoting the translation of numerous mRNAs encoding ribosomal proteins, such as 
RPS13, EEF1G and EIF4A [59]. Additionally, through the LIN28A/LIN28B-mediated inhibition of let-7, PI3K/AKTmTOR signaling may promote ribosomal biogenesis and translation in mammary cells via activating S6, eIF4E and eIF4B, as let-7 is known to target key components of this pathway, such as AKT2 and Raptor [60, 61]. A detailed discussion of the LIN28A/LIN28B-mediated activation of cellular metabolism and subsequent promotion of cellular proliferation is presented in the next section.

Of note, under certain conditions, LIN28A/LIN28B may also inhibit cancer cell proliferation. Indeed, Song et al. reported that over-expression of LIN28A/LIN28B in gastric cancer cell line BGC-823 inhibited proliferation through some unknown mechanism [62]. However, as the authors used only one cell line, whether LIN28A/ LIN28Btruly inhibits proliferation of gastric cancer cells is still not clear. Moreover, since extensive elevation of oncoproteins, such as RAS, MYC and RAF, can induce cell senescence and/or apoptosis [53], the reported inhibition may have been the result of cell senescence triggered by extensive proliferative signals.

\section{LIN28A/LIN28B and let-7 loop regulates cancer cell metabolism}

Metabolic shift is a basic property of cancer cells. In the 1920s, Otto Warburg discovered that glycolysis was maintained in cancer cells in conditions of high oxygen tension, otherwise known as "aerobic glycolysis". During enhanced glucose uptake and elevated glycolysis, intermediates of the glycolytic pathway become a major resource for anabolic reactions in cancer cells. For example, dihydroxyacetone phosphate is important for synthesis of triacylglycerides and phospholipids, glucose 6-phosphate is necessary for the synthesis of glycogen and ribose 5-phosphate, and pyruvate is an important progenitor of amino acids and may enter a truncated tricarboxylic acid (TCA) cycle and generate acetyl-CoA, which is necessary for the synthesis of fatty acids, cholesterol and isoprenoids. Thus, through augmenting anabolic reactions, glycolysis is a promoter of cancer cell growth and proliferation [63]. Both LIN28A and LIN28B reportedly enhance aerobic glycolysis, while let-7 suppresses this process at least in part through targeting pyruvate dehydrogenase kinase 1(PDK1), which negatively regulates pyruvate dehydrogenase (PDH), thus preventing pyruvate entry into TCA under normoxic conditions [64]. LIN28A/LIN28B also directly potentiates cellular metabolism through binding and regulating translation of glycolysis enzymes such as hexokinase 1 (HK1), pyruvate dehydrogenase alpha 1 (PDHA1) and PDHB [59].

Insulin signaling is a master regulator of cellular anabolic metabolism [65]. By activing the PI3K/AKT pathway through binding insulin receptors, insulin not only facilitates glucose uptake and promotes glycogenesis, but also promotes protein synthesis and lipogenesis. Thus, insulin-PI3K/AKT signaling is a key regulator coupling cellular anabolic metabolism with cellular growth and proliferation. Through let-7, LIN28A/LIN28B activates insulin signaling by elevating components involved in insulin signaling pathways, such as IGF1R, insulin receptor (InsR), IRS2, AKT2 and Rictor (Fig. 2) [60]. LIN28A/ LIN28Balso directly activates insulin signaling through binding and activating translation of components and regulators of insulin signaling pathways, such asIGF2 and HMGA1. IGF2 is a ligand of InsR, and the interaction between IGF2 and InsR triggers the activation of

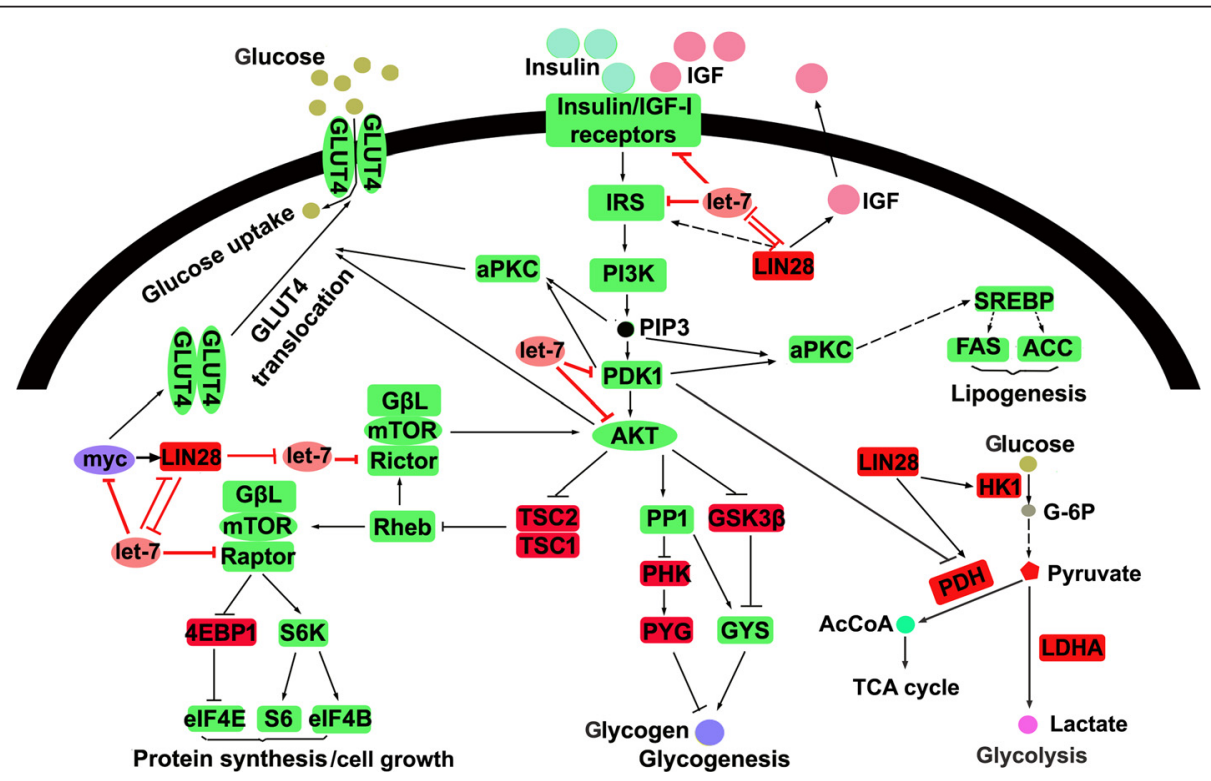

Fig. 2 Let-7 targets insulin signaling pathway and thus inhibits cancer cell metabolism 
insulin signaling. HMGA1 is a key regulator of the transcription of InsR [66].

\section{LIN28A/LIN28B and let-7 loop mediates cancer cell evasion of immune destruction}

The immune system is responsible for recognizing and eliminating cancer cells; however, tumors typically evade immune destruction through either avoiding detection by the immune system or limiting the extent of immunological eradication [53]. Recent studies suggest that the LIN28A/LIN28B and let-7 loop may also regulate cancer cell immune evasion.

The transmembrane protein Fas (CD95) is a member of the tumor necrosis factor (TNF) receptor superfamily. Binding of either Fas ligand (Fas-L), a type II transmembrane protein expressed on cytotoxic T lymphocytes, or TNF $\alpha$, a cytokine secreted by activated macrophages and other immune cells, induces trimerization of Fas in the membrane of the target cell (including cancer cells) and results in the activation of Fas. Fas activation then leads to the activation of caspase 8 , triggering extrinsic apoptosis [67]. Let-7 expression has been shown to decrease during Fas-mediated apoptosis because Fas activation suppresses Dicer; however, exogenous expression of let-7 inhibits cell sensitivity to Fas-mediated apoptosis via directly targeting Fas [43, 68], which suggests that let-7 family miRNAs may suppress tumor innate immune reactions.

Toll-like receptors (TLRs) are a class of transmembrane proteins expressed in macrophages, neutrophils, dendritic cells and other immune cells, and play a key role in innate immune response via recognizing inflammatory mediators, costimulatory molecules and even conserved structures of microbes. Peptides, lipopolysaccharides and nucleic acids may each act as TLR ligands [69]. TLRs are universally expressed in many cancer types and promote the development of inflammation-associated malignances through activating the inflammatory response. However, TLRs have also been shown to be sensors of cell death, and stimulation of TLRs to activate the innate immune system is a strategy currently under development for cancer therapy [69]. A recent study uncovered that extracellular let-7 interacts with and then activates TLR7, an RNA-sensing neuronal TLR, and induces neurodegeneration [70]. Interestingly, in a metastatic gastric cancer cell line, let-7 family miRNAs could be selectively secreted into the extracellular environment via exosomes [71]. These results suggest that the activation of TLR7 induced by extracellular let-7 may also be involved in the regulation of immune response or inflammation in cancer; however, this hypothesis has yet to be validated experimentally.

\section{LIN28A/LIN28B and let-7 loop mediates tumor-associated} inflammation

Inflammation is linked clinically and epidemiologically to cancer. However, the molecular intersections between inflammation and cancer progression have been unclear for a long time. Recently, it was demonstrated that the LIN28A/LIN28B and let-7 loop is a key switch linking inflammation to cell transformation. Viswanathan et al. were the first to evaluate the role of LIN28A in cell transformation, over-expressing LIN28A in NIH/3 T3 cells [12]. They observed that LIN28A over-expression promoted $3 \mathrm{~T} 3$ cells to form clones in vitro and form solid tumors in nude mice with a concomitant downregulation of multiple mature let- 7 family member miRNAs. Importantly, this effect could be attenuated by reintroducing let-7. Recently, a consistent result was observed by Madison et al. in intestinal epithelial cells. They showed that targeted expression of LIN28B promoted crypt transformation and fostered intestinal polyp and adenocarcinoma formation in vivo in a let-7dependent manner [72]. In revisiting the molecular intersection between inflammation and cancer progression, Dimitrios and colleagues revealed such an intersection between inflammation and cell transformation [27]. They showed that over-expression of LIN28B upon the activation of NF-kB inhibited the generation of let-7 family member miRNAs and elevated the production of IL-6, a target of let-7. In turn, IL-6 activated NF- $\mathrm{kB}$ and STAT3 transcription factors through the RTK signaling pathway. The activation of NF- $\mathrm{kB}$ and subsequent production of IL-6 thus formed a positive feedback loop (Fig. 3), while STAT3 activation is necessary for the transformation of normal cells. Furthermore, they showed that STAT3 directly activated miR-181b and miR-21 at the transcriptional level. MiR-181b and miR-21 target cylindromatosis (CYLD) and phosphatase and tensin homolog (PTEN), respectively, and down-regulation of CYLD and PTEN leads to NF- $\mathrm{KB}$ activation, therefore also acting as a part of the epigenetic switch linking inflammation to cancer [73]. As previously mentioned, STAT3 also suppresses the expression of let-7 through directly activating LIN28A/LIN28B expression during inflammation-stimulated EMT [28].

\section{LIN28A/LIN28B and let-7 loop regulates metastasis}

Local invasion and distant metastasis are marks of higher pathological stages of malignant cancers. While the invasion-metastasis cascade is known to consist of a succession of processes, beginning with local invasion and followed by intravasation (cancer cell invasion into blood and lymphatic vessels) and extravasation (cancer cell escape from vessels) to form micrometastases and finally grow into macroscopic tumors, the mechanisms involved in this multistep process are still being defined. Of all the steps, however, local invasion is the most extensively studied. 


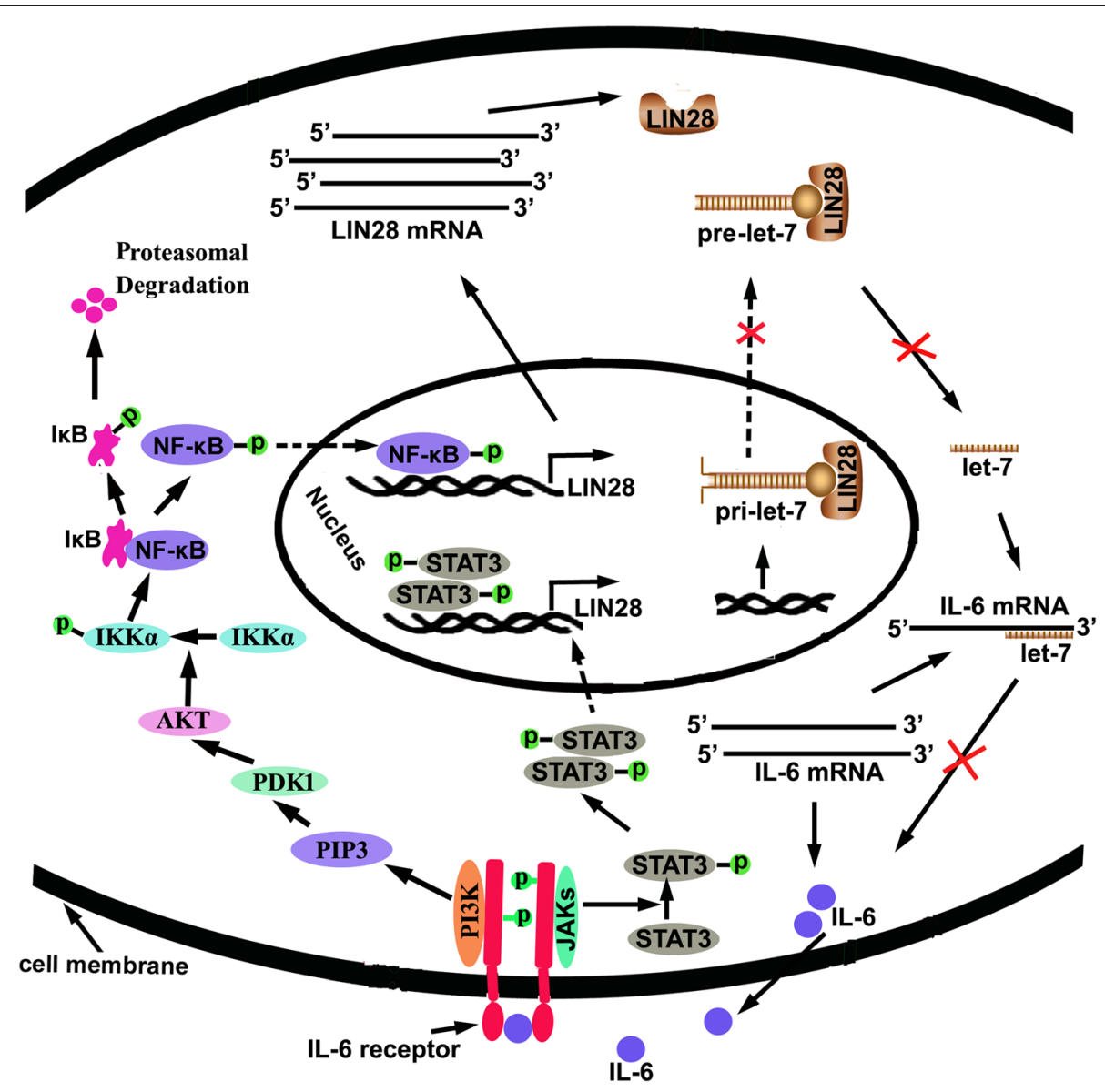

Fig. 3 A positive feedback between LIN28A/LIN28B and transcriptional factor NF-KB and STAT3 in the process of inflammation mediated cancer progression

EMT is broadly believed to regulate invasion [53]. EMT is characterized as epithelial cells losing their cell polarity and cell-cell adhesion with the loss of Ecadherin expression usually driven by the elevated expression of a set of transcriptional factors, such as Snail, Slug, Twist and Zeb1/2 [53]. Involvement of the LIN28A/LIN28B and let-7 loop in the regulation of cancer cell invasion and metastasis is, naturally, intimately associated with EMT. Many studies have shown that LIN28A/LIN28B promotes and let-7 inhibits invasion and metastasis in various cancer types, including colon cancer, breast cancer, hepatocellular carcinoma, pancreatic cancer, gastric cancer, lung cancer and esophageal cancer [57, 74-79]. In fact, the mechanism by which let-7 inhibits invasion and metastasis is, actually, wellstudied. HMGA2 is the most frequently reported target of let-7 in the process of inhibiting invasion and metastasis [57, 77]. HMGA2 has been demonstrated to promote EMT by inducing the expression of Slug and Snail and then inhibiting the expression of E-cadherin in many cancer types $[57,80]$. In addition to regulating invasion and metastasis via a coding gene, HMGA2 also functions as a ceRNA to facilitate cancer metastasis in certain cancer types [52]. As previously mentioned, by competing with TGFBR3 to bind let-7, HMGA2 represses the inhibitory effect of let-7 on TGFBR3, thus elevating TGFBR3protein and facilitating cancer invasion and metastasis [52]. BesidesHMGA2, let-7 also was reported to inhibit invasion, migration and metastasis via targetingITGB3, MAP4K3 and MYH9 [76, 79]. A recent study showed that let-7 inhibited the cancer cell migration via direct targeting of four genes in the actin cytoskeletal pathway, including RDX, DIAPH2, ITGB8 and PAK1 [81]. IL-6 was also a direct target of let-7 to inhibit cancer cell invasion and migration. It was reported that down-regulation oflet-7 in cancer-associated mesenchymal stem cells (MSCs) results in the enhanced secretion of IL-6, and IL- 6 then promotes prostate cancer cell metastasis [82]. LIN28A/LIN28B promotes invasion and metastasis through the let-7/HMGA2/Slug or Snail/Ecadherin axis $[57,77]$, but also in a let-7-independent manner. LIN28A directly binds and promotes the translation 
of HMGA1, and like HMGA2, HMGA1 promotes EMT by inducing the expression of Slug and Snail. Additionally, LIN28A has been found to directly bind E-cadherin mRNA and repress the translation of E-cadherin mRNA in embryo stem cells [83]; however, the role of LIN28Ain directly regulating E-cadherin expression in cancer cells is still unclear.

\section{LIN28A/LIN28B and let-7 loop regulates cancer cell death}

The LIN28A/LIN28B and let-7 axis is known to regulate cellular apoptosis and is involved in resistance/sensitivity to therapy. Many studies have shown that the overexpression of let-7 or knockdown of LIN28A/LIN28B increases the radiosensitivity or chemosensitivity of cancer cells [84-87]. Let-7 reportedly induces cellular apoptosis through targeting the anti-apoptotic protein B-cell lymphoma-extra large (BCL-XL) in many cell types [86-88] as well as the IL-6/STAT3 pro-survival pathway [89]. While LIN28A/LIN28B represses apoptosis via let-7, it may also regulate the expression of pro-apoptosis and/or anti-apoptosis genes through unidentified mechanisms. For example, over-expression of LIN28B in oral cancer cells promotes the expression of Survivin, an apoptosis inhibitor [90].

Recently, the existence of a subclass of neoplastic cells, termed cancer stem cells (CSCs), in many tumors is thought to be the root cause of chemotherapeutic failure and tumor recurrence because CSCs are resistant to apoptosis [53]. While the LIN28A/LIN28B and let-7 loop is known to be involved in the development of chemotherapeutic sensitivity of cancer cells to apoptosis, it is also purportedly involved in the maintenance and/or differentiation of CSCs. Firstly, in many cancer types, high levels of LIN28A and other stem cell maintenance factors, such as OCT4, are present in a sub-population of cells with CSC properties [91-93]. Secondly, forced expression of LIN28A promotes the expression of CSC markers as well as the self-renewal capability of CSCs, while knock-down has the opposite effect [74, 92]. Lastly, through the down-regulation of let-7, enhanced expression of LIN28A induced the development of CSC 'stemness' coupled with resistance to chemotherapyinduced apoptosis [94, 95].

Of note, let-7 may inhibit apoptosis under certain conditions. For example, forced let-7a expression in A431 and HepG2 cells increased resistance to apoptosis induced by doxorubicin and paclitaxel through the direct targeting of caspase-3 [96]. Additionally, up-regulation of let-7 family miRNA expression upon estrogen exposure in endometrial adenocarcinoma enhanced cellular survival through the direct targeting of the anti-apoptosis gene BAX [97]. These results suggest that the let-7 family miRNAs play a multifaceted role in the regulation of cellular apoptosis.
LIN28A/LIN28B and let-7 loop regulates genome instability In normal cells, the stability and integrity of the genome is maintained by a functional DNA damage repair system. However, in cancer cells, this system is often defective resulting in genome instability and the accelerated accumulation of mutations. While these effects are typically necessary for and contribute to cancer progression, certain mutations may also be deadly for cancer cells or increase their sensitivity to various therapeutic modalities [53]. In radiation-treated cancer cells, LIN28A/ LIN28B over-expression reportedly inhibits the expression of gamma-H2AX, which is an activate form of histone H2AX and is necessary for repair of double strand breaks (DSBs) [98], which suggests that LIN28A/LIN28B may increase genome instability by inhibiting DSB repair [85]. However, a recent study found that the expression of let-7 was decreased in colon cancer cells following radiation exposure [99]. Another study showed that p53 directly bound to and inhibited the expression of let-7 during this process [99]. Moreover, the exogenous expression of let-7 increased radiation-induced cytotoxicity, which suggests that let-7 family miRNAs may also increase the genomeinstability of cancer cells.

\section{LIN28A/LIN28B and let-7 loop may regulate other hallmarks of cancer}

Angiogenesis is required for tumors to survive as they need a steady supply of nutrients and oxygen as well as a means of evacuating metabolic waste. The most thoroughly-studied inducer of angiogenesis is vascular endothelial growth factor (VEGF). A recent study showed that stable expression of LIN28B in oral cancer cells promoted the expression of VEGF, suggesting that LIN28A/ LIN28B may be involved in the regulation of tumor angiogenesis [90].

To generate macroscopic tumors, cancer cells also have to acquire the capability of replicative immortality, partially through conquering senescence, a barrier to proliferation and characterized as irreversible entrance into a nonproliferative but viable state [53]. Cellular senescence involves transcriptional repression of proliferation-promoting genes mediated by the retinoblastoma (RB1)/E2F transcriptional repressor complex. Interestingly, let-7 reportedly triggers human cell senescence through modifying chromatin at the promoters of RB1/E2F target genes, thus repressing their transcription, which suggests that the LIN28A/LIN28B and let-7 loop may also be involved in the regulation of cancer cellular replicative immortality [100].

\section{Crosstalk between LIN28/let-7 loop and oncogenes in regulating hallmarks of cancer}

Transcription factor myc is a well-established oncogene. More than $70 \%$ of all tumors have some form of c-MYC 
gene dysregulation [101]. It has been well-known that myc controls the proliferation of cancer cells. Recently, it has also been shown that myc regulates the metabolism, cancer related inflammation, metastasis, angiogenesis, and genome instability of malignancies. Thus, myc is a master regulator to control the progression of malignancies via mediating crosstalk of hallmarks of cancer.

The function of myc in regulating the proliferation of cancer cells has been well-documented. Myc directly transactivates most of the critical positive cell cycle regulators (such as Cdks and cyclins) but block the transcription of cell cycle inhibitors (such as p21). Moreover, myc directly promotes DNA replication by facilitating the replication initiation and hyperactivatescyclin/Cdk complexes via activation of Cdc25 phosphatases and Cdk activating kinase (CAK) [102]. In addition to regulate proliferation, the myc oncogene was shown to enhance glycolysis and alter amino acid metabolism in cancer cells [103]. Myc is known to directly activate the expression of almost all genes encoding glycolytic enzymes, such as lactate dehydrogenase (LDH), hexokinase 2 and enolase 1. Also, myc enhances glucose uptake via activating the expression of the glucose transporter GLUT1 [103, 104]. Besides glucose, cancer cells also take up and use glutamine to accumulate biomass. Glutamine is converted into glutamate by glutaminase (GLS), and glutamate drives the biogenesis of acetyl-CoA through a reverse TCA cycle. Myc promotes glutaminolysis and the generation of glutamate through activating the expression of GLS. As previously states, the activation of tumor associated macrophage (M2 type macrophage) showed pro-tumorigenic behavior. The data from Pello et al. demonstrated that the activation of tumor-associated macrophage requires the transcription factor $\mathrm{c}-\mathrm{MYC}$, and c-MYC controls the induction of about $45 \%$ of genes associated with M2 macrophage activation, such as SCARB1, ALOX15 and MRC1; whereas myc inhibition prevents the activation of M2 macrophages and their protumorigenic behavior [105]. Myc also regulates metastasis of malignancies [106]. It not only promotes EMT of cancer cells through activation of SNAIL and HMGA2, but also facilitates the invasion and migration of cancer cells via directly activating transcription of a bunch of invasion or migration-promoting factors, such as LGALS1, OPN and RhoA [106]. It has been demonstrated that myc is essential for the vasculogenesis and angiogenesis during tumor progression [107]. The mechanisms of myc masterly regulating angiogenesis was associated with that myc directly activates the expression of VEGF, a potent angiogenesis inducer, but indirectly inhibits the expression of angiogenesis inhibitors thrombospondin-1 through induction of miR-17-92 cluster [108]. Additionally, myc induced genome instability has been noticed recently [101]. Myc was revealed to affect genome amplifications, nucleus organization [101] and impair DNA damage repairs $[109,110]$.

It has been revealed that c-myc can directly bind the promoter of LIN28B and thus elevate the production of LIN28B and consequently inhibit the generation of let-7 family of miRNAs upon activation of MAPK signaling

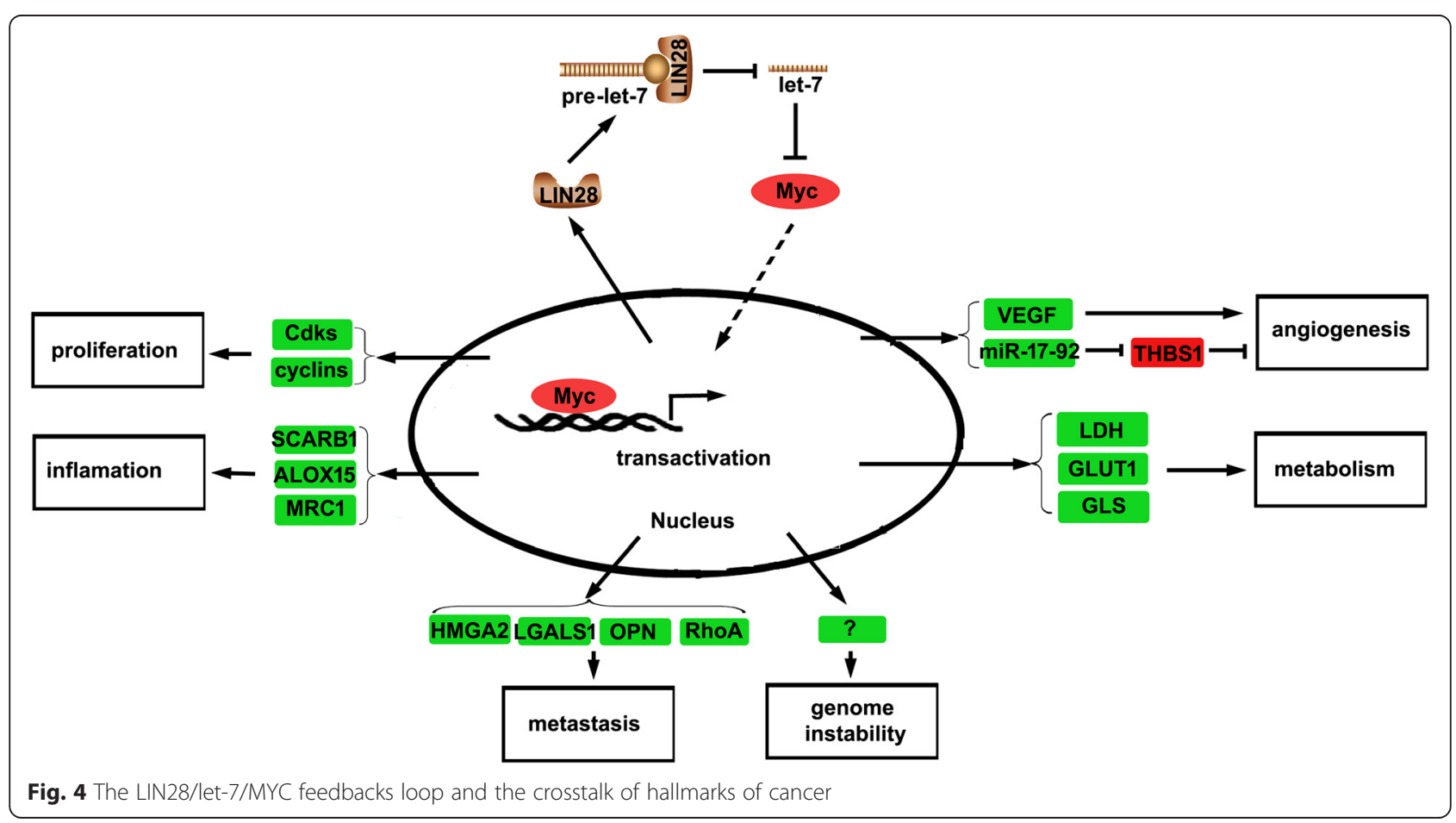


[26]. Interestingly, over-expression of LIN28 was shown to elevate the expression of myc via down-regulation of let-7, which targets the MYC gene. These results suggested a complicated feedback loop consisting of LIN28B, let-7 and MYC. Since myc is one of the target genes of let-7, let-7-mediated inhibition of myc thus inhibits the crosstalk of hallmarks of cancers; LIN28A/ LIN28B, of course, has the opposite effect. The LIN28/ let-7/MYC feedbacks loop and the crosstalk of hallmarks of cancer has been shown in Fig. 4.

The expression of LIN28/let-7/MYC feedbacks is regulated by many signaling pathways and oncogenes. When Wnt signals are absent, the cytoplasm $\beta$-catenin is degraded by APC/GSK3 $\beta /$ Axin complex, while Wnt ligands bind to Frizzled receptor, cytoplasm $\beta$-catenin is accumulated and translocates to the nucleus where $\beta$ catenin promotes the transcription of myc gene [111]. This implies that $\beta$-catenin may also indirectly upregulate LIN28 expression via elevating myc level. Recently, it has been reported that $\beta$-catenin can directly promote the transcription of LIN28B [29]. Growth factors binding to their receptors result in the activation of RAS, which either activates ERK (MAPK signaling) or PI3K/AKT signaling. ERK directly activates the transcription of myc, while AKT indirectly promotes the expression of myc gene via activating $\beta$-catenin activity [111], which suggests that RAS may regulate the expression of LIN28. Indeed, RAS has been found to inhibit the generation of let-7 by upregulating the expression of LIN28 via MAPK activated myc expression [26]. AKT also activates the NF- $\mathrm{B}$ signaling via activating IKK, and NF- $\mathrm{KB}$ has been reported to directly promotes the transcription of LIN28B and thus inhibits the generation of let-7 s [27]. Interestingly, RAS and AKT are the direct targets of let-7 $\mathrm{s}$ respectively $[60,112]$. These results suggested that there is a complicated crosstalk between RAS, PI3K/AKT, NF-кB, LIN28A/LIN28B and let-7 loop. The crosstalk between these oncogenes and LIN28A/ LIN28B and let-7 loop is summarized in Fig. 5.

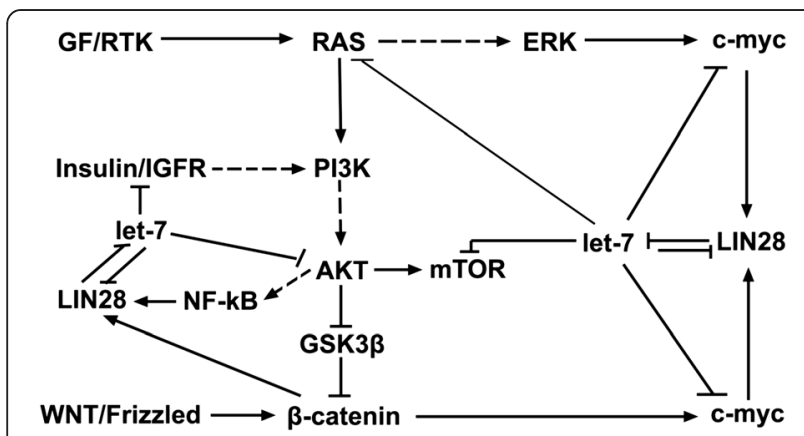

Fig. 5 Crosstalk between LIN28/let-7 loop and oncogenes in regulating hallmarks of cancer

\section{Conclusion and perspective}

In summary, in a variety of cancer types, let- 7 is most frequently down-regulated, while LIN28A/LIN28B is most frequently up-regulated, and the aberrant expression of one component of theLIN28A/LIN28B and let-7 loop due to transcriptional and/or post-transcriptional level dysregulation in human malignant tumors would result in the alteration of the other one. High levels of LIN28A/LIN28B and low levels of let-7 contribute to the development of human malignances through promoting cellular proliferation, cell death resistance, angiogenesis, metastasis, metabolism reprogramming, tumor-associated inflammation, genome instability, acquiring immortality and evading immune destruction of cancer cells. The many established studies suggest that the LIN28A/LIN28B and let-7 loop is a master regulator of cancer development and would be a valuable target for future cancer therapeutic strategies.

\section{Competing interests}

The authors declare that they have no competing interests.

\section{Authors' contributions}

$\mathrm{XL}, \mathrm{NN}$ and DW conceived and organized the topic. TW, GW, DH and XL reviewed lectures and wrote the manuscript. All authors read and approved the final manuscript.

\section{Acknowledgement}

We thank Ms. Ning Shen for her preparation of figures, and thank Mr. Chao Yang for his management of literatures. This work is partially supported by the National Natural Science Foundation of China (Grant No. 81302061 to Tianzhen Wang; Grant No. 81201688 to Ning Ning; Grant No. 81401961 to Xiaobo Li), Postdoctoral scientific research development fund of Heilongjiang Province (Grant No. LBH-Q14104 to Xiaobo Li), Wu-Lian-De Youth Science Foundation of Harbin Medical University (Grant No.WLD-QN1411 to Xiaobo Li), The Natural Science Foundation of Heilongjiang Province of China (Grant No.C2015027 to Dong Wang), The Scientific Research Fund of Heilongjiang Provincial Education Department (Grant No.12541426 to Dong Wang) and Hospital Foundation of Inner Mongolia Autonomous Region People's Hospital (Grant No. 201301 to Xi Liu).

\section{Author details}

${ }^{1}$ Department of Pathology, Harbin Medical University, Harbin, China. ${ }^{2}$ Department of Gastrointestinal Medical Oncology, The Affiliated Tumor Hospital of Harbin Medical University, Harbin, China. ${ }^{3}$ Faculty of Health Sciences, University of Macau, Taipa, Macau, China. ${ }^{4}$ Center of Cardiovascular, Inner Mongolia People's Hospital, Hohhot, Inner Mongolia, China. ${ }^{5}$ College of Bioinformatics Science and Technology, Harbin Medical University, Harbin, China. ${ }^{6}$ Department of Gastrointestinal Surgery, International Hospital of Pecking University, Beijing, China.

Received: 24 May 2015 Accepted: 24 June 2015 Published online: 30 June 2015

\section{References}

1. Lee Y, Kim M, Han J, Yeom KH, Lee S, Baek SH, et al. MicroRNA genes are transcribed by RNA polymerase II. 2004.

2. Yi R, Qin Y, Macara IG, Cullen BR. Exportin-5 mediates the nuclear export of pre-microRNAs and short hairpin RNAs. Genes Dev. 2003;17:3011-6.

3. Reinhart BJ, Slack FJ, Basson M, Pasquinelli AE, Bettinger JC, Rougvie AE, et al. The 21-nucleotide let-7 RNA regulates developmental timing in Caenorhabditis elegans. Nature. 2000;403:901-6.

4. Rodini CO, Suzuki DE, Saba-Silva N, Cappellano A, de Souza JE, Cavalheiro S, et al. Expression analysis of stem cell-related genes reveal OCT4 as a predictor of poor clinical outcome in medulloblastoma. J Neurooncol. 2012;106:71-9. 
5. Sakurai M, Miki Y, Masuda M, Hata S, Shibahara Y, Hirakawa H, et al. LIN28: a regulator of tumor-suppressing activity of let-7 microRNA in human breast cancer. J Steroid Biochem Mol Biol. 2012;131:101-6.

6. Roush S, Slack FJ. The let-7 family of microRNAs. Trends Cell Biol. 2008;18:505-16

7. Horvitz HR, Sulston JE. Isolation and genetic characterization of cell-lineage mutants of the nematode Caenorhabditis elegans. Genetics. 1980;96:435-54.

8. Ambros $V$, Horvitz HR. Heterochronic mutants of the nematode Caenorhabditis elegans. Science. 1984;226:409-16.

9. Guo Y, Chen Y, Ito H, Watanabe A, Ge X, Kodama T, et al. Identification and characterization of lin-28 homolog B (LIN28B) in human hepatocellular carcinoma. Gene. 2006;384:51-61.

10. Thornton JE, Gregory RI. How does Lin28 let-7 control development and disease? Trends Cell Biol. 2012;22:474-82.

11. Shyh-Chang N, Daley GQ. Lin28: primal regulator of growth and metabolism in stem cells. Cell Stem Cell. 2013;12:395-406.

12. Viswanathan SR, Powers JT, Einhorn W, Hoshida Y, Ng TL, Toffanin S, et al. Lin28 promotes transformation and is associated with advanced human malignancies. Nat Genet. 2009;41:843-8.

13. Balzer $\mathrm{E}$, Moss $\mathrm{EG}$. Localization of the developmental timing regulator Lin28 to mRNP complexes, P-bodies and stress granules. RNA Biol. 2007:4:16-25.

14. Newman MA, Thomson JM, Hammond SM. Lin-28 interaction with the Let-7 precursor loop mediates regulated microRNA processing. RNA. 2008;14:1539-49.

15. Piskounova E, Polytarchou C, Thornton JE, LaPierre RJ, Pothoulakis C, Hagan JP, et al. Lin28A and Lin28B inhibit let-7 microRNA biogenesis by distinct mechanisms. Cell. 2011;147:1066-79.

16. Mayr F, Heinemann U. Mechanisms of Lin28-mediated miRNA and mRNA regulation-a structural and functional perspective. Int J Mol Sci. 2013;14:16532-53.

17. Nam Y, Chen C, Gregory RI, Chou JJ, Sliz P. Molecular basis for interaction of let-7 microRNAs with Lin28. Cell. 2011;147:1080-91.

18. Loughlin FE, Gebert LF, Towbin H, Brunschweiger A, Hall J, Allain FH. Structural basis of pre-let-7 miRNA recognition by the zinc knuckles of pluripotency factor Lin28. Nat Struct Mol Biol. 2012;19:84-9.

19. Piskounova E, Viswanathan SR, Janas M, LaPierre RJ, Daley GQ, Sliz P, et al. Determinants of microRNA processing inhibition by the developmentally regulated RNA-binding protein Lin28. J Biol Chem. 2008;283:21310-4.

20. Hagan JP, Piskounova E, Gregory RI. Lin28 recruits the TUTase Zcchc11 to inhibit let-7 maturation in mouse embryonic stem cells. Nat Struct Mol Biol. 2009;16:1021-5

21. Heo I, Joo C, Kim YK, Ha M, Yoon MJ, Cho J, et al. TUT4 in concert with Lin28 suppresses microRNA biogenesis through pre-microRNA uridylation. Cell. 2009;138:696-708

22. Heo I, Joo C, Cho J, Ha M, Han J, Kim VN. Lin28 mediates the terminal uridylation of let-7 precursor MicroRNA. Mol Cell. 2008;32:276-84.

23. Mullen TE, Marzluff WF. Degradation of histone mRNA requires oligouridylation followed by decapping and simultaneous degradation of the mRNA both $5^{\prime}$ to $3^{\prime}$ and $3^{\prime}$ to $5^{\prime}$. Genes Dev. 2008;22:50-65.

24. Chang HM, Triboulet R, Thornton JE, Gregory RI. A role for the Perlman syndrome exonuclease Dis312 in the Lin28-let-7 pathway. Nature. 2013:497:244-8.

25. Kolenda T, Przybyla W, Teresiak A, Mackiewicz A, Lamperska KM. The mystery of let-7d - a small RNA with great power. Contemp Oncol (Pozn). 2014;18:293-301.

26. Chang TC, Zeitels LR, Hwang HW, Chivukula RR, Wentzel EA, Dews M, et al. Lin-28B transactivation is necessary for Myc-mediated let-7 repression and proliferation. Proc Natl Acad Sci U S A. 2009;106:3384-9.

27. Iliopoulos D, Hirsch HA, Struhl K. An epigenetic switch involving NF-kappaB, Lin28, Let-7 MicroRNA, and IL6 links inflammation to cell transformation. Cell. 2009;139:693-706

28. Guo L, Chen C, Shi M, Wang F, Chen X, Diao D, et al. Stat3-coordinated Lin28-let-7-HMGA2 and miR-200-ZEB1 circuits initiate and maintain oncostatin M-driven epithelial-mesenchymal transition. Oncogene. 2013;32:5272-82.

29. Cai WY, Wei TZ, Luo QC, Wu QW, Liu QF, Yang M, et al. The Wnt-beta-catenin pathway represses let-7 microRNA expression through transactivation of Lin28 to augment breast cancer stem cell expansion. J Cell Sci. 2013;126:2877-89.

30. Cimadamore F, Amador-Arjona A, Chen C, Huang CT, Terskikh AV. SOX2-LIN28/ let-7 pathway regulates proliferation and neurogenesis in neural precursors. Proc Natl Acad Sci U S A. 2013;110:E3017-26.

31. Fu X, Meng Z, Liang W, Tian $Y$, Wang $X$, Han W, et al. miR-26a enhances miRNA biogenesis by targeting Lin28B and Zcchc11 to suppress tumor growth and metastasis. Oncogene. 2014;33:4296-306.
32. Fuchs $H$, Theuser M, Wruck W, Adjaye J. miR-27 negatively regulates pluripotency-associated genes in human embryonal carcinoma cells. PLoS One. 2014;9:e111637.

33. Faria AM, Sbiera S, Ribeiro TC, Soares IC, Mariani BM, Freire DS, et al. Expression of LIN28 and its regulatory microRNAs in adult adrenocortical cancer. Clin Endocrinol (Oxf). 2014;82(4):481-8.

34. Li X, Zhang J, Gao L, McClellan S, Finan MA, Butler TW, et al. MiR-181 mediates cell differentiation by interrupting the Lin2 8 and let-7 feedback circuit. Cell Death Differ. 2012;19:378-86.

35. Borrego-Diaz E, Powers BC, Azizov V, Lovell S, Reyes R, Chapman B, et al. A potential regulatory loop between Lin28B:miR212 in androgen-independent prostate cancer. Int J Oncol. 2014;45:2421-9.

36. Kim CW, Vo MT, Kim HK, Lee HH, Yoon NA, Lee BJ, et al. Ectopic over-expression of tristetraprolin in human cancer cells promotes biogenesis of let-7 by down-regulation of Lin28. Nucleic Acids Res. 2012;40:3856-69.

37. Segalla S, Pivetti S, Todoerti K, Chudzik MA, Giuliani EC, Lazzaro F, et al. The ribonuclease DIS3 promotes let-7 miRNA maturation by degrading the pluripotency factor LIN28B mRNA. Nucleic Acids Res. 2015;43(10):5182-93.

38. Jonson L, Christiansen J, Hansen TV, Vikesa J, Yamamoto Y, Nielsen FC. IMP3 RNP safe houses prevent miRNA-directed HMGA2 mRNA decay in cancer and development. Cell Rep. 2014;7:539-51.

39. Lee SH, Cho S, Kim MS, Choi K, Cho JY, Gwak HS, et al. The ubiquitin ligase human TRIM71 regulates let-7 microRNA biogenesis via modulation of Lin28B protein. Biochim Biophys Acta. 2014;1839:374-86.

40. Thomson JM, Newman M, Parker JS, Morin-Kensicki EM, Wright T, Hammond SM. Extensive post-transcriptional regulation of microRNAs and its implications for cancer. Genes Dev. 2006;20:2202-7.

41. Sakamoto S, Aoki K, Higuchi T, Todaka H, Morisawa K, Tamaki N, et al. The NF90-NF45 complex functions as a negative regulator in the microRNA processing pathway. Mol Cell Biol. 2009;29:3754-69.

42. Diederichs $S$, Haber DA. Dual role for argonautes in microRNA processing and posttranscriptional regulation of microRNA expression. Cell. 2007;131:1097-108

43. Geng L, Zhu B, Dai BH, Sui CJ, Xu F, Kan T, et al. A let-7/Fas double-negative feedback loop regulates human colon carcinoma cells sensitivity to Fasrelated apoptosis. Biochem Biophys Res Commun. 2011:408:494-9.

44. Haselmann V, Kurz A, Bertsch U, Hubner S, Olempska-Muller M, Fritsch J, et al. Nuclear death receptor TRAIL-R2 inhibits maturation of let-7 and promotes proliferation of pancreatic and other tumor cells. Gastroenterology. 2014;146:278-90.

45. Brueckner B, Stresemann C, Kuner R, Mund C, Musch T, Meister M, et al. The human let-7a-3 locus contains an epigenetically regulated microRNA gene with oncogenic function. Cancer Res. 2007;67:1419-23.

46. Lu L, Katsaros D, de la Longrais IA, Sochirca O, Yu H. Hypermethylation of let-7a-3 in epithelial ovarian cancer is associated with low insulin-like growth factor-ll expression and favorable prognosis. Cancer Res. 2007:67:10117-22.

47. Bethke A, Fielenbach N, Wang Z, Mangelsdorf DJ, Antebi A. Nuclear hormone receptor regulation of microRNAs controls developmental progression. Science. 2009;324:95-8.

48. Hammell CM, Karp X, Ambros V. A feedback circuit involving let-7-family miRNAs and DAF-12 integrates environmental signals and developmental timing in Caenorhabditis elegans. Proc Natl Acad Sci U S A. 2009;106:18668-73.

49. Salmena L, Poliseno L, Tay Y, Kats L, Pandolfi PP. A ceRNA hypothesis: the Rosetta Stone of a hidden RNA language? Cell. 2011;146:353-8.

50. Denzler R, Agarwal V, Stefano J, Bartel DP, Stoffel M. Assessing the ceRNA hypothesis with quantitative measurements of miRNA and target abundance. Mol Cell. 2014;54:766-76.

51. Kallen AN, Zhou XB, Xu J, Qiao C, Ma J, Yan L, et al. The imprinted H19 IncRNA antagonizes let-7 microRNAs. Mol Cell. 2013;52:101-12.

52. Kumar MS, Armenteros-Monterroso E, East P, Chakravorty P, Matthews N, Winslow MM, et al. HMGA2 functions as a competing endogenous RNA to promote lung cancer progression. Nature. 2014;505:212-7.

53. Hanahan D, Weinberg RA. Hallmarks of cancer: the next generation. Cell. 2011;144:646-74

54. Xu B, Zhang K, Huang Y. Lin28 modulates cell growth and associates with a subset of cell cycle regulator mRNAs in mouse embryonic stem cells. RNA. 2009;15:357-61.

55. Feng C, Neumeister V, Ma W, Xu J, Lu L, Bordeaux J, et al. Lin28 regulates HER2 and promotes malignancy through multiple mechanisms. Cell Cycle. 2012;11:2486-94. 
56. Wang $Y$, Lu Y, Toh ST, Sung WK, Tan $P$, Chow $P$, et al. Lethal-7 is down-regulated by the hepatitis $B$ virus $x$ protein and targets signal transducer and activator of transcription 3. J Hepatol. 2010;53:57-66.

57. Chen KJ, Hou Y, Wang K, Li J, Xia Y, Yang XY, et al. Reexpression of Let-7g microRNA inhibits the proliferation and migration via K-Ras/HMGA2/snail axis in hepatocellular carcinoma. Biomed Res Int. 2014;2014:742417.

58. Zhang K, Gao H, Wu X, Wang J, Zhou W, Sun G, et al. Frequent overexpression of HMGA2 in human atypical teratoid/rhabdoid tumor and its correlation with let-7a3/let-7b miRNA. Clin Cancer Res. 2014;20:1179-89.

59. Peng $S$, Chen LL, Lei XX, Yang L, Lin H, Carmichael GG, et al. Genome-wide studies reveal that Lin28 enhances the translation of genes important for growth and survival of human embryonic stem cells. Stem Cells. 2011;29:496-504.

60. Zhu H, Shyh-Chang N, Segre AV, Shinoda G, Shah SP, Einhorn WS, et al. The Lin28/let-7 axis regulates glucose metabolism. Cell. 2011;147:81-94.

61. Frost RJ, Olson EN. Control of glucose homeostasis and insulin sensitivity by the Let-7 family of microRNAs. Proc Natl Acad Sci U S A. 2011;108:21075-80.

62. Song $H, X u$ W, Song J, Liang Y, Fu W, Zhu XC, et al. Overexpression of Lin28 inhibits the proliferation, migration and cell cycle progression and induces apoptosis of BGC-823 gastric cancer cells. Oncol Rep. 2015;33:997-1003.

63. Kroemer G, Pouyssegur J. Tumor cell metabolism: cancer's Achilles' heel. Cancer Cell. 2008:13:472-82.

64. Ma X, Li C, Sun L, Huang D, Li T, He X, et al. Lin28/let-7 axis regulates aerobic glycolysis and cancer progression via PDK1. Nat Commun. 2014;5:5212.

65. Saltiel AR, Kahn CR. Insulin signalling and the regulation of glucose and lipid metabolism. Nature. 2001:414:799-806.

66. Brunetti A, Manfioletti G, Chiefari E, Goldfine ID, Foti D. Transcriptional regulation of human insulin receptor gene by the high-mobility group protein HMGI(Y). Faseb j. 2001;15:492-500.

67. Wajant H. Principles and mechanisms of CD95 activation. Biol Chem. 2014;395:1401-16.

68. Wang S, Tang Y, Cui H, Zhao X, Luo X, Pan W, et al. Let-7/miR-98 regulate Fas and Fas-mediated apoptosis. Genes Immun. 2011;12:149-54.

69. Li TT, Ogino S, Qian ZR. Toll-like receptor signaling in colorectal cancer: carcinogenesis to cancer therapy. World J Gastroenterol. 2014;20:17699-708.

70. Lehmann SM, Kruger C, Park B, Derkow K, Rosenberger K, Baumgart J, et al. An unconventional role for miRNA: let-7 activates Toll-like receptor 7 and causes neurodegeneration. Nat Neurosci. 2012;15:827-35.

71. Ohshima K, Inoue K, Fujiwara A, Hatakeyama K, Kanto K, Watanabe Y, et al. Let-7 microRNA family is selectively secreted into the extracellular environment via exosomes in a metastatic gastric cancer cell line. PLoS One. 2010;5:e13247.

72. Madison BB, Liu Q, Zhong X, Hahn CM, Lin N, Emmett MJ, et al. LIN28B promotes growth and tumorigenesis of the intestinal epithelium via Let-7. Genes Dev. 2013;27:2233-45.

73. Hiopoulos D, Jaeger SA, Hirsch HA, Bulyk ML, Struhl K. STAT3 activation of miR-21 and miR-181b-1 via PTEN and CYLD are part of the epigenetic switch linking inflammation to cancer. Mol Cell. 2010;39:493-506.

74. King CE, Cuatrecasas M, Castells A, Sepulveda AR, Lee JS, Rustgi AK. LIN28B promotes colon cancer progression and metastasis. Cancer Res. 2011;71:4260-8.

75. Hamano R, Miyata H, Yamasaki M, Sugimura K, Tanaka K, Kurokawa Y, et al. High expression of Lin28 is associated with tumour aggressiveness and poor prognosis of patients in oesophagus cancer. Br J Cancer. 2012;106:1415-23.

76. Liang S, He L, Zhao X, Miao Y, Gu Y, Guo C, et al. MicroRNA let-7f inhibits tumor invasion and metastasis by targeting MYH9 in human gastric cancer. PLoS One. 2011;6:e18409.

77. Dangi-Garimella S, Yun J, Eves EM, Newman M, Erkeland SJ, Hammond SM, et al. Raf kinase inhibitory protein suppresses a metastasis signalling cascade involving LIN28 and let-7. Embo j. 2009;28:347-58.

78. Ma C, Nong K, Zhu H, Wang W, Huang X, Yuan Z, et al. H19 promotes pancreatic cancer metastasis by derepressing let-7's suppression on its target HMGA2-mediated EMT. Tumour Biol. 2014;35:9163-9.

79. Zhao B, Han H, Chen J, Zhang Z, Li S, Fang F, et al. MicroRNA let-7C inhibits migration and invasion of human non-small cell lung cancer by targeting ITGB3 and MAP4K3. Cancer Lett. 2014;342:43-51.

80. Li Y, Zhao Z, Xu C, Zhou Z, Zhu Z, You T. HMGA2 induces transcription factor slug expression to promote epithelial-to-mesenchymal transition and contributes to colon cancer progression. Cancer Lett. 2014;355:130-40.

81. Hu X, Guo J, Zheng L, Li C, Zheng TM, Tanyi JL, et al. The heterochronic microRNA let-7 inhibits cell motility by regulating the genes in the actin cytoskeleton pathway in breast cancer. Mol Cancer Res. 2013;11:240-50.

82. Sung SY, Liao CH, Wu HP, Hsiao WC, Wu IH, Jinpu Y, et al. Loss of let-7 microRNA upregulates IL-6 in bone marrow-derived mesenchymal stem cells triggering a reactive stromal response to prostate cancer. PLoS One. 2013:8:e71637.

83. Cho J, Chang H, Kwon SC, Kim B, Kim Y, Choe J, et al. LIN28A is a suppressor of ER-associated translation in embryonic stem cells. Cell. 2012;151:765-77.

84. Ren J, Chu Y, Ma H, Zhang Y, Zhang X, Zhao D, et al. Epigenetic interventions increase the radiation sensitivity of cancer cells. Curr Pharm Des. 2014;20:1857-65.

85. Wang L, Yuan C, Lv K, Xie S, Fu P, Liu X, et al. Lin28 mediates radiation resistance of breast cancer cells via regulation of caspase, H2A.X and Let-7 signaling. PLoS One. 2013;8:e67373.

86. Shimizu S, Takehara T, Hikita H, Kodama T, Miyagi T, Hosui A, et al. The let-7 family of microRNAs inhibits BCl-xL expression and potentiates sorafenibinduced apoptosis in human hepatocellular carcinoma. J Hepatol. 2010;52:698-704

87. Tian N, Han Z, Li Z, Zhou M, Fan C. Lin28/let-7/BCl-xL pathway: the underlying mechanism of drug resistance in Hep3B cells. Oncol Rep. 2014;32:1050-6.

88. Qin B, Xiao B, Liang D, Li Y, Jiang T, Yang H. MicroRNA let-7C inhibits BCl-xl expression and regulates ox-LDL-induced endothelial apoptosis. BMB Rep. 2012;45:464-9.

89. Sugimura K, Miyata H, Tanaka K, Hamano R, Takahashi T, Kurokawa Y, et al. Let-7 expression is a significant determinant of response to chemotherapy through the regulation of IL-6/STAT3 pathway in esophageal squamous cell carcinoma. Clin Cancer Res. 2012;18:5144-53.

90. Wu T, Jia J, Xiong X, He H, Bu L, Zhao Z, et al. Increased expression of Lin28B associates with poor prognosis in patients with oral squamous cell carcinoma. PLoS One. 2013;8:e83869.

91. Peng S, Maihle NJ, Huang Y. Pluripotency factors Lin28 and Oct4 identify a sub-population of stem cell-like cells in ovarian cancer. Oncogene. 2010:29:2153-9.

92. Kong D, Banerjee S, Ahmad A, Li Y, Wang Z, Sethi S, et al. Epithelial to mesenchymal transition is mechanistically linked with stem cell signatures in prostate cancer cells. PLoS One. 2010;5:e12445.

93. Yang X, Lin X, Zhong X, Kaur S, Li N, Liang S, et al. Double-negative feedback loop between reprogramming factor LIN28 and microRNA let-7 regulates aldehyde dehydrogenase 1-positive cancer stem cells. Cancer Res. 2010;70:9463-72.

94. Yu F, Yao H, Zhu P, Zhang X, Pan Q, Gong C, et al. let-7 regulates self renewal and tumorigenicity of breast cancer cells. Cell. 2007;131:1109-23.

95. Meirelles K, Benedict LA, Dombkowski D, Pepin D, Preffer Fl, Teixeira J, et al. Human ovarian cancer stem/progenitor cells are stimulated by doxorubicin but inhibited by Mullerian inhibiting substance. Proc Natl Acad Sci U S A. 2012;109:2358-63.

96. Tsang WP, Kwok TT. Let-7a microRNA suppresses therapeutics-induced cancer cell death by targeting caspase-3. Apoptosis. 2008;13:1215-22.

97. Zhang $R, H e Y$, Zhang $X$, Xing $B$, Sheng $Y$, Lu H, et al. Estrogen receptorregulated microRNAs contribute to the $B C L 2 / B A X$ imbalance in endometrial adenocarcinoma and precancerous lesions. Cancer Lett. 2012;314:155-65.

98. Dickey JS, Redon CE, Nakamura AJ, Baird BJ, Sedelnikova OA, Bonner WM. H2AX: functional roles and potential applications. Chromosoma. 2009:118:683-92.

99. Saleh AD, Savage JE, Cao L, Soule BP, Ly D, DeGraff W, et al. Cellular stress induced alterations in microRNA let-7a and let-7b expression are dependent on p53. PLoS One. 2011;6:e24429.

100. Benhamed M, Herbig U, Ye T, Dejean A, Bischof O. Senescence is an endogenous trigger for microRNA-directed transcriptional gene silencing in human cells. Nat Cell Biol. 2012;14:266-75.

101. Kuzyk A, Mai S. c-MYC-induced genomic instability. Cold Spring Harb Perspect Med. 2014:4:a014373.

102. Bretones G, Delgado MD, Leon J. Myc and cell cycle control. Biochim Biophys Acta. 2015;1849:506-16.

103. Li B, Simon MC. Molecular pathways: targeting MYC-induced metabolic reprogramming and oncogenic stress in cancer. Clin Cancer Res. 2013;19:5835-41.

104. Dang CV. Therapeutic targeting of Myc-reprogrammed cancer cell metabolism. Cold Spring Harb Symp Quant Biol. 2011;76:369-74.

105. Pello OM, De Pizzol M, Mirolo M, Soucek L, Zammataro L, Amabile A, et al. Role of c-MYC in alternative activation of human macrophages and tumorassociated macrophage biology. Blood. 2012;119:411-21.

106. Wolfer A, Ramaswamy S. MYC and metastasis. Cancer Res. 2011;71:2034-7.

107. Baudino TA, McKay C, Pendeville-Samain H, Nilsson JA, Maclean KH, White EL, et al. c-Myc is essential for vasculogenesis and angiogenesis during development and tumor progression. Genes Dev. 2002;16:2530-43. 
108. Whitfield JR, Soucek L. Tumor microenvironment: becoming sick of Myc. Cell Mol Life Sci. 2012;69:931-4.

109. Ambrosio S, Amente S, Napolitano G, Di Palo G, Lania L, Majello B. MYC impairs resolution of site-specific DNA double-strand breaks repair. Mutat Res. 2015;774:6-13.

110. Muvarak N, Kelley S, Robert C, Baer MR, Perrotti D, Gambacorti-Passerini C, et al. C-MYC generates repair errors via increased transcription of alternativeNHEJ factors, LIG3 and PARP1, in tyrosine kinase-activated leukemias. Mol Cancer Res. 2015;13:699-712.

111. Du W, Liu X, Fan G, Zhao X, Sun Y, Wang T, et al. From cell membrane to the nucleus: an emerging role of E-cadherin in gene transcriptional regulation. J Cell Mol Med. 2014;18:1712-9.

112. Bussing I, Slack FJ, Grosshans H. let-7 microRNAs in development, stem cells and cancer. Trends Mol Med. 2008;14:400-9.

113. King CE, Wang L, Winograd R, Madison BB, Mongroo PS, Johnstone CN, et al. LIN28B fosters colon cancer migration, invasion and transformation through let-7-dependent and -independent mechanisms. Oncogene. 2011;30:4185-93.

114. Ruzzo A, Graziano F, Vincenzi B, Canestrari E, Perrone G, Galluccio N, et al. High let-7a microRNA levels in KRAS-mutated colorectal carcinomas may rescue anti-EGFR therapy effects in patients with chemotherapy-refractory metastatic disease. Oncologist. 2012;17:823-9.

115. Pan L, Gong Z, Zhong Z, Dong Z, Liu Q, Le Y, et al. Lin-28 reactivation is required for let-7 repression and proliferation in human small cell lung cancer cells. Mol Cell Biochem. 2011:355:257-63.

116. Takamizawa J, Konishi H, Yanagisawa K, Tomida S, Osada H, Endoh H, et al. Reduced expression of the let-7 microRNAs in human lung cancers in association with shortened postoperative survival. Cancer Res. 2004;64:3753-6.

117. Yin X, Li YW, Jin JJ, Zhou Y, Ren ZG, Qiu SJ, et al. The clinical and prognostic implications of pluripotent stem cell gene expression in hepatocellular carcinoma. Oncol Lett. 2013;5:1155-62.

118. Ji J, Zhao L, Budhu A, Forgues M, Jia HL, Qin LX, et al. Let-7g targets collagen type I alpha2 and inhibits cell migration in hepatocellular carcinoma. J Hepatol. 2010;52:690-7.

119. Hu Q, Peng J, Liu W, He X, Cui L, Chen X, et al. Lin28B is a novel prognostic marker in gastric adenocarcinoma. Int J Clin Exp Pathol. 2014;7:5083-92.

120. Torrisani J, Bournet B, du Rieu MC, Bouisson M, Souque A, Escourrou J, et al. let-7 MicroRNA transfer in pancreatic cancer-derived cells inhibits in vitro cell proliferation but fails to alter tumor progression. Hum Gene Ther. 2009;20:831-44.

121. Helland A, Anglesio MS, George J, Cowin PA, Johnstone CN, House CM, et al. Deregulation of MYCN, LIN28B and LET7 in a molecular subtype of aggressive high-grade serous ovarian cancers. PLoS One. 2011;6:e18064.

122. Dahiya N, Sherman-Baust CA, Wang TL, Davidson B, Shih le M, Zhang Y, et al. MicroRNA expression and identification of putative miRNA targets in ovarian cancer. PLoS One. 2008:3:e2436.

123. West JA, Viswanathan SR, Yabuuchi A, Cunniff K, Takeuchi A, Park IH, et al. A role for Lin28 in primordial germ-cell development and germ-cell malignancy. Nature. 2009:460:909-13.

124. Tummala R, Nadiminty N, Lou W, Zhu Y, Gandour-Edwards R, Chen HW, et al. Lin28 promotes growth of prostate cancer cells and activates the androgen receptor. Am J Pathol. 2013;183:288-95.

125. Nadiminty N, Tummala R, Lou W, Zhu Y, Shi XB, Zou JX, et al. MicroRNA let-7c is downregulated in prostate cancer and suppresses prostate cancer growth. PLoS One. 2012;7:e32832.

126. Leucci E, Cocco M, Onnis A, De Falco G, van Cleef P, Bellan C, et al. MYC translocation-negative classical Burkitt lymphoma cases: an alternative pathogenetic mechanism involving miRNA deregulation. J Pathol. 2008:216:440-50

127. Sampson VB, Rong NH, Han J, Yang Q, Aris V, Soteropoulos P, et al. MicroRNA let-7a down-regulates MYC and reverts MYC-induced growth in Burkitt lymphoma cells. Cancer Res. 2007;67:9762-70.

128. Heinzelmann J, Henning B, Sanjmyatav J, Posorski N, Steiner T, Wunderlich $\mathrm{H}$, et al. Specific miRNA signatures are associated with metastasis and poor prognosis in clear cell renal cell carcinoma. World J Urol. 2011;29:367-73.
129. Malik F, Korkaya H, Clouthier SG, Wicha MS. Lin28 and HER2: two stem cell regulators conspire to drive aggressive breast cancer. Cell Cycle. 2012;11:2780-1.

130. Qin R, Zhou J, Chen C, Xu T, Yan Y, Ma Y, et al. LIN28 is involved in glioma carcinogenesis and predicts outcomes of glioblastoma multiforme patients. PLoS One. 2014;9:e86446.

131. Muller DW, Bosserhoff AK. Integrin beta 3 expression is regulated by let-7a miRNA in malignant melanoma. Oncogene. 2008;27:6698-706.

\section{Submit your next manuscript to BioMed Central and take full advantage of:}

- Convenient online submission

- Thorough peer review

- No space constraints or color figure charges

- Immediate publication on acceptance

- Inclusion in PubMed, CAS, Scopus and Google Scholar

- Research which is freely available for redistribution 